\title{
El documento electrónico. Un análisis desde el derecho cubano en tiempos de pandemia
}

The electronic document. An analysis from Cuban law in times of pandemic

Autores: Yanixet Milagro Formentín Zayas, Yaimara Martínez Sifontes, Idarmis Knight Soto

Para citar este artículo:

Formentín Zayas, Y., Martínez Sifontes, Y. y Soto, I. (2021). El documento electrónico. Un análisis desde el Derecho cubano en tiempos de pandemia. Derecho y Realidad, 19 (38), 187-203.

Derecho y Realidad | ISSN Impreso 1692-3936 | ISSN En línea 2619-5607

Vol. 19 - Número 38 | Julio - Diciembre de 2021 | pp. 187 - 203

DOl: https://doi.org/10.19053/16923936.v19.n38.2021.13698

(2)

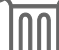




\section{EL DOCUMENTO ELECTRÓNICO. UN ANÁLISIS DESDE EL DERECHO CUBANO EN TIEMPOS DE PANDEMIA*}

The electronic document. An analysis from Cuban law in times of pandemic

\section{Yanixet Milagro Formentín Zayas}

Licenciada en Derecho. Máster en Derecho. Especialista en Asesoría Jurídica. Doctora en Ciencias Jurídicas. Profesora Titular. Coordinadora Maestría en Derecho Constitucional y Administrativo. Facultad de Ciencias Sociales. Universidad de Camagüey (Cuba).yanicet.formentin@reduc.edu.cu, yenima33@gmail.com ORCID 0000000221317733

\section{Yaimara Martínez Sifontes}

Licenciada en Derecho. Máster en Derecho. Facultad de Ciencias Sociales. Universidad de Camagüey (Cuba). yaimara.martinez@reduc.edu.cu

\section{Idarmis Knight Soto}

Licenciada en Derecho. Especialista en Asesoría Jurídica. Doctora en Ciencias Jurídicas. Profesora Titular de Derecho Internacional Público. Universidad de Ciego de Ávila, (Cuba) idarmis@unica.cu. ORCID 0000000347137488

Recepción: Agosto 27 de 2021

Aceptación: Septiembre 30 de 2021

\section{RESUMEN}

El presente artículo parte de la idea de que el tema de la prueba es fundamental para las partes de un proceso civil o mercantil, teniendo en cuenta que el éxito de sus pretensiones viene determinado, fundamentalmente, por la actividad probatoria desplegada a través de los medios de pruebas legalmente previstos, centrando nuestra atención en la fijeza que al hecho de probar ofrece el documento como medio de prueba de gran relevancia, ampliamente abordado en el ordenamiento procesal patrio, aunque su variante electrónica no ha corrido idéntica suerte. Se utilizaron los métodos de derecho comparado, teórico-jurídico, exegético, y el análisis síntesis, con el objetivo de analizar el documento electrónico como medio de prueba admisible en Cuba en tiempos de pandemia, haciendo especial referencia a su fuerza demostrativa y a la importancia de este para acreditar hechos o consolidar determinados actos concernientes al tráfico jurídico.

\section{PALABRAS CLAVES}

Prueba judicial; medios de prueba; proceso civil o mercantil; documento; documento electrónico.

\footnotetext{
* Artículo de reflexión
} 


\section{ABSTRACT}

This article is based on the idea that the issue of evidence is fundamental for the parties to a civil or commercial proceeding, taking into account that the success of their claims is determined, fundamentally, by the evidentiary activity deployed through the means of evidence legally provided for focusing our attention on the fixity that the fact of proving offers the document as a means of proof of great relevance, widely addressed in the national procedural system, although its electronic variant has not suffered the same fate. The methods of comparative law, theoretical-legal, exegetical, and synthesis analysis were used, with the aim of analyzing the electronic document as a means of admissible evidence in Cuba in times of pandemic making special reference to its demonstrative force and the importance of this to prove facts or consolidate certainctos concerning legal trafficking.

\section{KEYWORDS}

Judicial evidence; means of proof; civil or commercial proceedings; document; electronic document.

\section{INTRODUCCIÓN}

La sociedad cubana actual se ha visto impactada por la revolución tecnológica, trayendo consigo el avance de las nuevas tecnologías de la información y las comunicaciones, de suma importancia en la conducción de las relaciones jurídicas que se establecen entre las personas, por medio de la utilización de medios tecnológicos virtuales y menos presenciales.

Del mismo modo, la Organización Mundial de la Salud (OMS) declaró al Coronavirus (Covid-19) como una pandemia debido a su propagación mundial, lo que ha afectado simultáneamente a un gran número de personas durante un período de tiempo concreto, requiriendo una actuación específica en los ámbitos de prevención y tratamiento; Cuba no se ha visto exento de ello.
Todo lo anterior ha influido en el ámbito del derecho procesal, generando cambios en la actividad probatoria e imponiendo una nueva orientación en los medios de prueba tradicionales, si se tiene en cuenta que dadas las condiciones actuales, los hechos pueden registrarse en medios físicos y electrónicos, resultando los documentos electrónicos de vital trascendencia para la transmisión de datos en el quehacer cotidiano, al punto de considerarse que los de elaboración electrónica han remplazado a los documentos tradicionales.

Los estudios sobre la prueba documental, como medio de probanza, han sido profusos en la doctrina procesal foránea y en la academia nacional; sin embargo, en el caso específico del documento electrónico la complejidad de su uso y aceptación como fundamento de las decisiones de los jueces en la solución de un conflicto civil o mercantil, radica en la certeza de los mismos. Siendo así, la judicatura cubana ha de adaptarse a los nuevos cambios para lo cual tendrán que apartarse de los conceptos tradicionales de la prueba e ingresar al escenario jurídico con una visión tecnológica en garantía de los derechos fundamentales de las partes en el proceso. En esta línea estarán encaminadas nuestras enunciaciones.

\section{LA PRUEBA JUDICIAL. CONSIDERACIONES GENERALES}

La noción de prueba va más allá del ámbito del derecho, pues está presente en todas las esferas de la vida humana al ser sinónimo de comprobación, verificación, constatación. De ahí que, exista una noción ordinaria o vulgar de la prueba, al lado de una noción técnica, y que ésta varíe según la clase de actividad o de ciencia a la que se aplique (Devis-Hechandía, 2000, p. 16). La prueba judicial es sin más, una modalidad de la prueba, como actividad del ser humano en su interacción con la naturaleza y con la propia sociedad en que convive (Mantecón, 2016, p. 144).

Para el derecho, el término prueba tiene un carácter multívoco, lo que puede llegar a generar confusiones; por ejemplo, las 
normas procesales manejan técnicamente a la institución a través de distintas acepciones, en dependencia de a qué se orienta la idea de la prueba. Cabe hablar entonces de ella como actividad, medio y resultado.

En primer lugar, se puede identificar como una actividad que se desarrolla al interior del proceso, a través de la cual las partes aportan los antecedentes necesarios para sustentar sus alegaciones y el juzgador determina la cuestión fáctica debatida. En este sentido, la prueba aparece en un aspecto dinámico, integrada por una variedad de factores que se encuentran en constante movilidad, con intervención de los litigantes y del juez, de todo lo cual se obtiene la determinación de los hechos (Meneses, 2008, p. 45). Esta actividad es regulada por el procedimiento probatorio, entendido este como el conjunto de actos que se llevan a cabo para lograr la realización de la prueba en un proceso.

La prueba judicial aparece, además, como el medio o instrumento utilizado en el iter procesal para que el tribunal pueda dar por acreditadas las afirmaciones de hecho de la causa, así se habla de prueba de testigos o prueba documental.

Es también usado para identificar un resultado, consistente en la conclusión a la cual llega el juzgador sobre el factum probandum a partir de los antecedentes allegados al proceso. Corresponde a la parte final del procedimiento probatorio, y en esa dirección se dice que se logró la prueba que se esperaba del hecho litigioso, o sea que el hecho resultó probado.

Empero, doctrinalmente se define a la prueba en el proceso civil como la actividad procesal que tiende a alcanzar la certeza en el juzgador respecto de los datos apuntados por las partes, certeza que en unos casos se deriva del convencimiento psicológico del mismo juez y en otros de las normas legales que fijarán los hechos (Montero, 2007, p. 30).

De acuerdo con este concepto, se debe destacar que la doctrina probatoria actual no reconoce la distinción entre búsqueda de la verdad material (como finalidad del proceso penal) y búsqueda de la verdad formal (como misión del proceso civil), pues la verdad es o no es, no caben situaciones intermedias o aparentes. Al respecto, se acepta la idea de que en el proceso civil la función de la prueba judicial será propiciar certeza sobre los hechos o datos ventilados en el proceso, los que deben ser establecidos y fijados con la mayor correspondencia posible a la realidad, para poder arribar a una decisión sobre el conflicto.

A partir de la teoría general de la prueba, además del concepto al que ya se ha hecho referencia, existen otras situaciones importantes a tener en cuenta, tales como: qué se prueba, cuándo se alude a su objeto, quién prueba para hacer mención a la carga y cómo se prueba y qué valor tiene la prueba producida en el sentido de su valoración.

Con frecuencia se produce una confusión entre lo que constituye el objeto y tema de la prueba, lo que ocasiona que se desvirtúe la noción que se tiene sobre cada una de estas categorías, de ahí que se torne indispensable separarlas y explicarlas detalladamente:

- El objeto de la prueba busca respuesta a: ¿qué cosas pueden ser probadas? De manera general se refiere esta categoría al espacio dentro del cual puede moverse la actividad probatoria en el proceso. Es una noción puramente objetiva y abstracta, no limitada a los problemas concretos de cada proceso ni a las pretensiones de las partes.

- Por necesidad o tema de la prueba se entiende lo que en cada proceso en particular debe ser materia de la actividad probatoria, sin cuyo conocimiento el juez no puede decidir. También se manifiesta la relación entre una noción objetiva, porque no se contempla en ella la persona o parte que debe suministrar la prueba de esos hechos, sino en general el panorama probatorio del proceso; y, concreta, porque recae sobre hechos determinados que deben ser probados allí. 
En tal sentido la prueba puede recaer sobre:

- Las conductas humanas, los sucesos o acontecimientos, los hechos y los actos involuntarios o voluntarios, individuales o colectivos, sus circunstancias de tiempo, lugar y modo.

- Los hechos de la naturaleza.

- Las cosas u objetos materiales y los lugares, es decir cualquier aspecto de la realidad material, sea o no sea producto del hombre o sobre ellos haya incidido o no la actividad humana.

- La propia persona humana, en cuanto realidad material, tanto en lo que se refiere a su propia existencia como a sus condiciones físicas y mentales, sus aptitudes y cualidades.

- Los estados psíquicos o internos del hombre, en tanto sean determinantes de las relaciones jurídicas tuteladas en el proceso.

Excepcionalmente puede constituir objeto de la prueba una norma jurídica, siempre que la norma de cuya aplicación se trata sea de derecho extranjero, en cuyo caso lo que debe probarse es su vigencia ${ }^{1}$. Se entiende que el juez conoce el derecho nacional y la existencia de esta presunción de conocimiento del derecho, justifica el hecho de que el juez no requiere ser ilustrado sobre las normas jurídicas que aplicará, cuestión esta que tiene su fundamento en la publicidad $^{2}$.

1. Sentencia RC.000580 de Tribunal Supremo de Justicia, Sala de Casación Civil, del 6 de octubre de 2016, Venezuela.

2. En Cuba el tema de la publicidad de las leyes tiene asiento constitucional, específicamente en el artículo 165 de la Constitución, se estipula que las leyes y decretosleyes que emitan la Asamblea Nacional del Poder Popular o el Consejo de Estado, según corresponda, entran en vigor en la fecha que, en cada caso, determine la propia disposición normativa. Las leyes, decretosleyes, decretos presidenciales, decretos, resoluciones y demás disposiciones de interés general que se emitan por los órganos competentes se publican en la Gaceta Oficial de la República. La ley establece el procedimiento para la elaboración, publicación y entrada en vigor de las disposiciones normativas.
Ahora bien, no todo lo que se aporta al proceso por la actividad alegatoria de las partes constituye objeto de prueba. Entre ellas:

- Los hechos notorios por su publicidad y evidencia, entendidos estos como aquellos cuyo conocimiento forma parte de la cultura normal propia de un determinado círculo social, en el tiempo en que se produce la decisión judicial. La notoriedad es un concepto relativo, por cuanto lo que es de general conocimiento en un determinado lugar o momento puede no serlo en otro lugar o en otro momento distintos. De modo que se deben tener presentes las circunstancias concretas de tiempo y espacio.

- Los hechos confesados (admitidos) o no negados por las partes en los escritos polémicos, se trata de hechos que no son controvertidos, por tanto, la prueba que se proponga será impertinente. Esta regla viene consagrada en el artículo 260 de la Ley de Procedimiento Civil, Administrativo, Laboral y Económico (en lo adelante LPCALE) el que establece la inadmisión de las pruebas propuestas para verificar hechos confesados o admitidos en los escritos polémicos, disposición que debe acogerse con relatividad, sobre todo en los procesos de objeto indisponible.

- El hecho favorecido por una presunción, se refiere a las presunciones legales, las cuales a su vez pueden ser de derecho o simplemente legales. En todo caso se debe distinguir entre el hecho base o premisa y el hecho presumido propiamente tal. El hecho base o premisa debe estar probado, y sólo entonces puede darse por acreditado el hecho presumido. No obstante, incluso en este caso puede ser que el hecho presumido requiera prueba. En efecto, si la presunción es de derecho, hay exclusión de prueba y no se puede rendir prueba en contrario, pero si es simplemente legal, es admisible prueba por parte del que quiere destruir el hecho presumido. El artículo 350 de la LPCALE 
estipula que las presunciones que la ley establece, dispensan de toda prueba a los favorecidos por ellas.

Una vez instaurado lo que se debe probar, el juicio lógico conduce a preguntarse quién debe hacerlo, sin que la respuesta ofrezca mayores dificultades, pues el principio de aportación de parte determina que son las partes las que deben probar. Sobre ellas recae la carga de alegar los hechos que son el supuesto base de la norma cuya aplicación piden, y sobre ellas recae también la carga de probar la existencia de esos hechos.

El concepto de la carga de la prueba reviste gran importancia toda vez que impide que se produzca la situación conocida como la absolución de la instancia o non liquet, que existía en el derecho romano y en virtud de la cual, si no se acreditaban los hechos, el juez estaba obligado a sobreseer el proceso. Hoy en día, si no se rinde prueba, trae como consecuencia que el juez dicte sentencia desfavorable contra el que no sobrellevó la carga de la prueba.

La relación procesal, de manera general, no impone obligaciones a las partes entre las que se constituye, sino cargas. Según Goldschmidt (1936, p. 23), una carga es el ejercicio de un derecho para el logro del propio interés, es el poder o facultad de ejecutar libremente ciertos actos o adoptar cierta conducta provista en la norma para beneficio y en interés propio, sin sujeción ni coacción y sin que exista otro sujeto que tenga derecho a exigir su observancia, pero cuya inobservancia acarrea consecuencias desfavorables. En consecuencia, el depositario de una carga que no la cumple oportunamente, deja de recibir los beneficios específicos que se derivarían de haberla satisfecho debidamente.

Como regla general tendrá la carga de la prueba de un hecho controvertido aquella parte que lo afirmó. El artículo 244 de LPCALE dispone que a cada parte incumbe tanto probar los hechos que afirme como los que oponga a los alegados de la contraparte.
Una vez practicadas las pruebas propuestas por las partes en el proceso, el juez debe formarse juicios sobre todo el material aportado, fundamentalmente con criterios psicológicos y humanos (Ramos, 1985, p. 20). Dicha operación es sumamente compleja, pero a la vez necesaria, si se tiene en cuenta que la traducción de los hechos de la realidad la han realizado las partes, es por ello que se afirma que la valoración de las pruebas es el momento culminante y decisivo de la actividad probatoria al constituir el núcleo del razonamiento probatorio.

Por valoración de la prueba, según KISCH (1940), se puede entender que a la actividad intelectual que lleva a cabo el juez para medir la fuerza probatoria de un medio de prueba. Como se muestra es exclusiva del juez, define si la prueba cumple o no el fin procesal a que estaba destinada, de llevarle la convicción al juzgador, de ahí su importancia significativa.

Dentro de la apreciación de la prueba la doctrina más acabada distingue las operaciones de interpretar y valorar. Interpretar una prueba significa fijar el resultado, mientras que valorar una prueba supone otorgar la credibilidad que merece, atendiendo al sistema de valoración establecido por el legislador.

La primera operación mental a efectuar por el juez es la de interpretar el resultado de los medios de prueba, que significará fijar qué ha dicho el testigo, cuáles son las máximas de experiencia que aporta el perito o cuál es el contenido de un documento, por citar algunos ejemplos de los medios de prueba más habituales. Una vez verificada la interpretación, el juez debe proceder a su valoración, determinando la credibilidad del testigo, la razonabilidad de las máximas de experiencia aportadas por el perito y su aplicación al caso concreto, o si el documento es auténtico y refleja los hechos ocurridos en la realidad.

Para determinar la eficacia de los medios de prueba practicados en orden a establecer como ciertas las alegaciones que han sido objeto de aquéllos, dos posibilidades se ofrecen al legislador: hacer depender 
esa eficacia del razonamiento del juez (sistema de libre valoración de la prueba) o determinar legalmente el valor de la prueba en dependencia de los resultados de su práctica (sistema de valoración legal) y el sistema mixto.

Sobre el particular, se hará referencia al último sistema; es decir, el mixto, el cual es el resultado de la combinación de los dos sistemas anteriores y es el que más presencia tiene en los ordenamientos procesales civiles foráneos. El proceso civil cubano no está ajeno a esta realidad imperando un sistema mixto de valoración de las pruebas, así lo denota la LPCALE en los artículos 43, 280 y 294, entre otros.

El primero de ellos sigue un modelo de libre valoración de las pruebas al plantear que: "Los Tribunales al fallar apreciarán las pruebas de acuerdo con el valor que la Ley atribuya a cada una y ajustándose en todo caso a los principios de la razón y la ciencia". Por su parte el artículo 280 le da carácter de legal a la prueba de confesión cuando estipula que la misma hará prueba plena en cuanto perjudique al litigante que la preste. En cuanto a la prueba documental el artículo 294 refiere que: "Los documentos otorgados con la intervención de funcionario público con las formalidades legales, harán prueba plena entre las partes que en ellos hayan figurado, respecto a las declaraciones que contengan o que de ellas inmediatamente se deriven. Harán prueba, asimismo, aún respecto a terceros, en cuanto a su fecha y al motivo de su otorgamiento", concediéndole el carácter de prueba legal en cuanto a la eficacia o no del documento. Como se muestra siempre que cumplan con las disposiciones anteriores, cualquier medio documental puede ser prueba en el proceso civil, ahora hay que hacerse la pregunta: $i e l$ documento electrónico puede ser uno de estos medios de prueba posible bajo esta mixtura?

\section{EL DOCUMENTO COMO MEDIO DE PRUEBA}

Es uno de los medios del que pueden valerse las partes para constatar los hechos controvertidos es la prueba documental. Por tanto, desde el punto de vista procesal, el documento desempeña un papel importante para la acreditación de los hechos y datos de relevancia en el proceso.

La finalidad del documento que se presenta como medio de prueba es dejar creada constancia de los datos que se aportan al proceso, para que rijan en el tiempo. El documento es reflejo de su contenido, ya que reproduce un pensamiento o acto volitivo de una o ambas partes, por supuesto siempre que se enmarque en los límites objetivos de la actividad probatoria y sea contentivo de los requisitos de fehaciencia, exactitud y legitimidad, en cuya virtud se tendrán por eficaces.

Entre los principales elementos que componen la noción de documento (en un sentido amplio), se puede señalar, en primer término, que este es producto de un sujeto al que se le dice es su autor, el cual acredita su condición habitualmente mediante la firma del mismo, aunque el instrumento está destinado a vivir autónomamente y con independencia del sujeto que lo ha producido (Carnelutti, 1982, p. 15).

Normalmente se suele identificar el documento con un escrito, sin embargo, su concepto trasciende el marco del simple escrito, en consecuencia, existen otras materias que pueden servir de soporte físico a un documento como son las películas, cintas magnetofónicas, fotocopias, videos, discos duros de ordenadores, ficheros informatizados, inscripciones en piedra (Gómez-Colomer, 2001, p. 24). El problema sin duda se presenta al momento de introducirlo en el proceso y practicar la prueba.

De igual forma, también es importante el contenido del documento, pues este es útil como medio de prueba en cuanto que incorpora la representación de un pensamiento, de un conocimiento o de cualquier actividad humana. El documento vale como elemento representativo que permite a cualquier persona ajena a su autor enterarse del hecho que recoge. 
Atendiendo a su fuente emisora, estos pueden ser públicos o privados. Son públicos los autorizados por funcionarios públicos depositarios de la fe pública, ya sea notarial, administrativa o judicial. En cambio, los documentos privados son aquellos creados por particulares, sin que intervenga en su confección un funcionario público. Rige aquí el principio de libertad de formas pues las personas pueden redactar el documento de acuerdo a sus intereses particulares.

Sea público o privado, para que tenga fuerza probatoria, el documento debe ser auténtico. La autenticidad radica en la coincidencia de quien se dice ser el autor con quien realmente lo emitió (Gómez-Orbaneja, 2009, p. 23). Mientras que los públicos tienen a su favor una presunción de autenticidad, los privados generalmente requieren ser convalidados (reconocidos).

A tono con la doctrina procesal foránea la LPCALE no ofrece un concepto general de los documentos públicos, solo se limita a establecer las diferencias entre ambas clases de documentos. Los requisitos que deben cumplir los documentos para ser aceptados como medios de prueba documental son los dispuestos en el artículo 281 de la LPCALE ${ }^{3}$, el cual, para referirse a los documentos privados se refiere a los formados por particulares. Con esta definición, la clasificación de un documento como tal se reduce al criterio de su autoría o procedencia. Luego, por decantación negativa, se dispone que pertenezcan igualmente a esta clase

\footnotetext{
3. Otros requisitos de los medios de prueba son: Que el medio que se proponga este admitido por la Ley: Salvo los casos en que se adopta el principio de libertad de medios, que en realidad debería referirse a libertad de fuentes. Licitud de la prueba: Que la prueba haya sido obtenida lícitamente, o lo que es lo mismo que en su obtención no se vulneren derechos de las partes o de terceros. La licitud de la prueba es muy difícil de determinar, depende de la protección a los derechos individuales en otros cuerpos legales. Oportunidad: La prueba debe ser aportada en el momento procesal oportuno so pena de no ser admitida. Autenticidad: Se refiere a la autoría, para que el medio sea eficaz la fuente ha de ser auténtica, tienen que poder demostrarse cuál es su origen y quien es su destinatario. Integridad: Es un requisito apreciable para los documentos y se refiere a que los datos en ellos contenidos no pueden haber sido manipulados. Disponibilidad: El medio de prueba tiene que estar disponible para que el juez tenga acceso a él.
}

aquellos documentos que no quepan dentro de las categorías anteriores.

\section{EL DOCUMENTO ELECTRÓNICO. HACIA UN ANÁLISIS DESDE LA TEORÍA DE LA PRUEBA LITERAL EN EL DERECHO CIVIL CUBANO}

Teniendo en cuenta la noción más amplia de documento que lo concibe como una cosa capaz de representar un hecho, así como su concepción en el plano jurídico, aquello que representa hechos de relevancia jurídica, susceptibles de ser probados en un proceso judicial; no cabe dudas de que el documento electrónico es un documento en sí, como lo es toda cosa intervenida de algún modo por el hombre.

Ahora bien, ha sido cuestionada la idea de si el documento electrónico es técnicamente un documento, en el ámbito relativo al campo procesal civil, pues en tal contexto el documento está circunscrito al soporte en papel, circunstancia que también se ha dado en la esfera relativa al derecho civil sustantivo, en donde -específicamente en el ámbito propio de la realidad negocial-, el documento se ha vinculado en forma precisa a la manifestación de voluntades, con finalidad negocial.

Es por ello que, en correspondencia con el desarrollo de la noción documental electrónica, cabría preguntarse si tal categoría documental, puede ser integrada y comprendida dentro de la teoría documental propiamente civil.

Sobre el particular, existen dos posiciones, por un lado quienes sostienen que el documento electrónico tiene las mismas características que el documento tradicional en formato papel y, por tanto, es posible aplicarle toda la normativa pensada para la prueba documental clásica (Cervelló et al., 2000, p. 393) pero, en otro orden, están aquellos autores que defienden "la tesis opuesta: el documento informático no es un documento como los demás, sino que es un documento de especial naturaleza, que requiere, para su actuación práctica, una 
regulación específica, sin la cual no puede alcanzar de hecho una aceptable seguridad $\mathrm{y}$, por tanto, una apreciable difusión" (Pinochet-Olave, 2002, p. 23).

Lo cierto es que el documento electrónico, producto de su propia naturaleza informática, presenta desde el punto de vista probatorio civil una serie de debilidades a solucionar por la doctrina y jurisprudencia, como una categoría más de la realidad documental civil. En ese sentido, se hará alusión a un término que resulta para las autoras relevantes a la hora de definir tal cuestión, y este es el caso al estudio de la denominada teoría de la prueba literal, cuyo objeto de estudio es, específicamente, el análisis del escrito susceptible de prueba en juicio.

Siguiendo la doctrina tradicional, las investigadoras plantean que la denominada teoría de la prueba literal parte de un elemento básico: la de preeminencia del escrito para la prueba de las obligaciones, especialmente, en el ámbito civil. La preeminencia del escrito es una constante tanto en el ordenamiento jurídico cubano, como en el chileno, en el español, y en todos los ordenamientos jurídicos continentales europeos o de inspiración continental europea.

La cuestión de la escritura vinculada a la prueba literal tiene una relación estrecha con la seguridad jurídica de los diferentes actos, con lo que se demuestra la existencia de un hecho de notoria relevancia, constituyendo prueba fehaciente en todo proceso, pues el escrito permite preconstituir pruebas, conservarlas a lo largo del tiempo y dar publicidad a los contratos y negocios jurídicos en general. En términos más exactos se puede entender la prueba literal como el escrito destinado a probar la existencia de una situación jurídica.

Las doctrinas foránea y cubana hacen alusión a los dos elementos de la prueba literal; la escritura y la suscripción (Montero, 2007, p. 16) y (Mendoza, 2005, p. 62). La escritura es su elemento esencial, en cuanto contiene la expresión de ideas jurídicamente relevantes, y es el requisito exigido en términos explícitos por la ley, en tanto, que el segundo requisito referido a la conexión de la voluntad expresada en el documento con su autor se consigue, generalmente, por medio de la firma.

Sobre estos dos elementos, las autoras del artículo basarán la admisibilidad o no de la prueba documental electrónica, teniendo en cuenta el ordenamiento jurídico patrio.

La primera aproximación al tratamiento de la forma electrónica es su equiparación a la forma documental. Aplicables son a la forma electrónica las distintas teorías acerca de la naturaleza de los documentos (Carnelutti, 1940, p. 156); sin embargo, tal como se afirmó anteriormente esta equiparación tropieza con dos dificultades: la cuestión del soporte y de la firma.

Según la norma civil cubana los actos jurídicos, pueden efectuarse de manera expresa o tácita ${ }^{4}$. En interpretación de los preceptos civiles, los actos con forma expresa podrán realizarse mediante forma oral o escrita, u otra, al haberse empleado en el texto el verbo "puede", que reconoce la facultad de las partes como consecuencia de la cualidad dispositiva de esta norma. A pesar de que la norma civil cubana no recoge en sus preceptos que regulan la forma del acto jurídico una tendencia moderna y objetiva a la utilización de las nuevas tecnologías de la información, lo anterior no se descarta si se tiene en cuenta el concepto de escrito, por lo que los medios electrónicos ${ }^{5}$ presentan

4. Artículos 49 y 50 del C.C. La conclusión escrita del
contrato asegura, mejor que la conclusión oral, la prueba
y constancia ulterior del mismo, que no solo facilita la
labor del juez, sino también la de las partes que sabrán
con fijeza lo que pactaron y la de los terceros, que sabrán
a qué atenerse, evitando que los contratantes puedan
confabularse para defraudar sus derechos. En fin, con la
constancia escrita del contrato se consigna también una
mayor certidumbre y seguridad en tomo a la identidad de
las personas de los contratantes, su capacidad al tiempo
de celebrarse el contrato, y las circunstancias de tiempo
y lugar de celebración. La exigencia legal de que un acto
conste por escrito, tanto puede obedecer a un criterio de
forma como de prueba. En el primer sentido, el art 1.280
del C.C. español, en el segundo, el Statute of Frauds inglés
de 1676 (29 Caro n. C. 3) vigente, con ciertos matices,
tanto en Inglaterra como en los Estados Unidos.
5. Se entenderá por tales los dispositivos tecnológicos 
las características necesarias para ser considerados como tal.

Afín el criterio que acogen las normas contenidas en el artículo 15 de la Ley de las Notarías Estatales y el artículo 34 de su Reglamento, los cuales prevén la posibilidad de confeccionar los documentos notariales por cualquier medio de reproducción, entre los que se puede encontrar el electrónico. Tal enunciado -a criterio de las autorasno es suficiente para sostener la existencia del documento notarial electrónico, debido a que como presunción la propia norma prevista en el Reglamento establece el ajuste a determinados requisitos, entre los que se encuentra el estar en papel de la mejor calidad, lo que lleva a considerar que el precepto de cierta forma limita la utilización del documento notarial electrónico. El objetivo de dicha norma cuando se refiere a otro medio de reproducción, aunque pudiera ser el electrónico es solo para su realización, más no para su mantenimiento o almacenamiento.

El decreto-ley sobre la contratación económica establece la forma expresa o tácita de exteriorización de los contratos, y deja sentado que la regla escrita, puede ser de manera manuscrita, ya sea forma documental impresa o en soporte digital ${ }^{6}$.

para transmitir o almacenar datos e información, a través de computadoras, líneas telefónicas, enlaces dedicados, microondas o de cualquier otra tecnología.

6. Artículo 31.1 Decreto-Ley de Contratación. A diferencia de la legislación novel el artículo 51 del C. de C. partía del reconocimiento de la validez de los contratos con independencia de la forma en que se celebraran, siempre y cuando pudieran probarse por cualquiera de los medios establecidos en la ley. No era necesario que los contratos mercantiles se celebraran con forma escrita como requisito de validez, ni para probar su existencia, ya que podían ser probados por cualquiera de los medios de prueba dispuestos en la norma; lo que es muestra de espiritualismo que la caracterizaba. Este reconocía la validez de la correspondencia telegráfica como una de las formas que podrá tener el contrato con la condición de que los contratantes la hayan admitido con antelación en contrato escrito y con el cumplimiento de las condiciones o signos que hayan establecido. Dicho condicionamiento contradice la intención del legislador de reconocer y dar cabida en el código a los medios y tecnologías de comunicación como modo válido para la celebración del contrato y demuestra la falta de confianza en ellos, aun cuando su intensión fuera -contradictoriamenteresaltar su validez como medios de expresión de la voluntad contractual. El régimen jurídico de los contratos económicos en la Resolución 2253/2005 no se
El pronunciamiento de dicha disposición normativa lleva a pensar, en primera instancia de manera correcta, la existencia de la forma escrita en soporte digital; y, por otro lado, la no similitud del soporte documental con la forma documental.

Por tanto, acotando la materia objeto de estudio, en sentido amplio poseen forma electrónica todos aquellos negocios jurídicos que han sido constituidos por medio de un ordenador, cualquiera que sea la forma en que se presenten. Esto quiere decir que, salvo excepciones cualificadas, no se va a cuestionar la validez de los documentos electrónicos por motivos formales. Es decir, se permite la forma electrónica para la concertación de los contratos, lo que no será siempre posible debido a la existencia de límites establecidos en la doctrina civilista y en la ley a este propio principio. Los límites legales impuestos a la autonomía de la voluntad y a la libertad de forma se regulan de manera dispersa en la preceptiva del código civil. La forma escrita, ya sea privada o pública, es establecida unas veces con valor probatorio; y, otras, con carácter solemne o de publicidad.

En resumen, en el Derecho cubano la forma no condiciona siempre la validez de todos los contratos; no obstante, la forma escrita tiene una evidente presencia en el mundo de la contratación por su innegable utilidad (Formentin-Zayas, 2011, p. 359). De acuerdo con Ihering (1947) y Diez-Picazo (1993) produce ciertos efectos psicológicos, impide precipitaciones, introduce fijeza y certidumbre en el contrato y cuando es pública (rectius documento público notarial) tiene una especial eficacia legitimadora, ejecutiva, probatoria y registral. De ahí que, la forma electrónica pueda ser posible a los fines de la seguridad jurídica de los contratos y documentos que se realicen por este medio.

pronunciaba expresamente por ponderar la libertad de forma; aunque podía interpretarse de la indicación no. 3 , en la que reconocía la facultad que poseen las partes de acordar voluntariamente otros tipos de formalidades adicionales; ya que se determina la forma escrita con el único fin de la constancia o prueba del contrato, lo que posibilita la celebración o perfección con libertad de formas. 
Criterio diferente sostiene Chillón-Medina (2004, p. 515) para quien la forma escrita de celebración del contrato por vía electrónica se ve imposibilitada de ser satisfecha, debido a la ausencia del reconocimiento expreso de la validez de los mensajes de datos para el logro de los efectos del documento escrito en la celebración contractual. Desde una perspectiva funcional, la forma electrónica puede cumplir las mismas funciones que la forma tradicional. A pesar de lo anterior se sustenta la opinión de que la equiparación tropieza con dos dificultades esenciales:

- La primera es que el derecho cubano, como todos los de la familia romanogermánica y a diferencia de los de raíz anglosajona, establece una distinción fundamental entre documentos públicos y privados. El documento público por excelencia es el documento notarial, en cuya confección el notario ha de observar una serie de reglas que dan como resultado las funciones del instrumento. Quizás por influencia del derecho anglosajón, en la literatura sobre esta materia se omite esta distinción, lo que conduce a encaminar la forma electrónica solo desde el punto de vista de las funciones de los documentos privados.

- $\quad$ En segundo lugar, las características físicas del soporte legible por medios electrónicos ofrecen diferencias importantes con los soportes tradicionales. En realidad, la cuestión de si los textos en forma electrónica pueden ser considerados un "escrito" a los efectos establecidos en las leyes civiles y procesales civiles se escinde en dos: el requisito del soporte en sí, y el requisito de la firma manuscrita, que lleva a pensar en su flexible equiparación.

\section{EL DOCUMENTO ELECTRÓNICO. SU ADMISIBILIDAD EN CUBA EN TIEMPOS DE PANDEMIA}

En correspondencia con lo anterior, cuando la norma excepciona el principio de libertad de forma y requiere la escritura como requisito de celebración de los contratos, con valor solemne, determina las escrituras públicas o privadas.

En una primera valoración, las escrituras públicas y privadas pueden ser sustituidas por documentos electrónicos sin afectar la cualidad autoral, puesto que podrán tanto el oficial público como los particulares, incorporar el clausulado contractual en un documento electrónico y de esta forma contratar, siempre que cumplan con las exigencias establecidas en la ley.

Entre los requisitos reconocidos para la escritura privada figura la firma del contrato por las partes; requerimiento que no se encuentra exigido en los artículos reguladores de los contratos que tienen a la escritura privada como requisito esencial, sino que se infiere del artículo 288 de la LPCALE, al regular el cotejo de firmas y letras como medio para la impugnación de documentos privados, elemento que será analizado posteriormente.

En el caso del documento público, la solemnidad se materializa en escritura pública, en estos se presentan requisitos que no pueden obviarse; por tanto, a pesar de la consideración que realiza la legislación notarial vigente sobre la forma electrónica, su materialización se imposibilita, a no ser que se realicen modificaciones de las normas notariales que limitan el soporte, la firma y la concepción físico-espacial de los comparecientes.

Con respecto a la utilización, tiene una relación expresa con la publicidad que es exigida en determinados contratos, tal es el caso de los artículos 108 y 396.2 del Código civil, y de los contratos mercantiles en sentido general, donde la publicidad constituye una característica propia de los actos de comercio y los empresarios, las empresas en perfeccionamiento empresarial, así como de aquellos contratos que tengan por objeto bienes inmuebles. La publicidad es desarrollada a partir de la inscripción del acto en los registros correspondientes, por lo que la posibilidad de llevar estos actos en formato electrónico depende en 
primera instancia de los diferentes registros y de los requerimientos para la inscripción, que en cierta forma son los que limitan su materialización en soporte electrónico y mantienen la vigencia del soporte papel para dichos actos, lo que no quiere decir que con posibles modificaciones normativas se materialice la utilización de la inscripción por los medios electrónicos.

En lo que se refiere al valor probatorio, existe la posibilidad de admitir el documento electrónico como medio de prueba, sin cambios trascendentales en sus normas. La función probatoria del documento escrito en papel, en igual sentido podrá ser desempeñada por el documento electrónico, en el caso de que determinado contrato celebrado por vía electrónica tenga previsto en la norma la forma escrita para ser probado. Los requisitos que deberán cumplir los documentos electrónicos para ser aceptados como medios de prueba documental son los dispuestos en el artículo 281 de la LPCALE; requisitos que son acogidos por el proyecto de norma especial que tiene como objeto la regulación del empleo de los medios electrónicos en el comercio ${ }^{7}$.

En Cuba, a diferencia de otros países ${ }^{8}$, no existe todavía una legislación específica del documento electrónico, lo que es considerado para muchos expertos como limitante para impregnarle un pleno valor jurídico a estos, lo que es incorrecto, unido al poco desarrollo de las nuevas tecnologías y a la falta de cultura informática de no solo los operadores del derecho, sino de todos los ciudadanos en general.

Sin embargo, es dable analizar como la LPCALE al regular en su artículo 299 la prueba documental manifiesta que en esta

7. El proyecto de Decreto-Ley de comercio electrónico, en los artículos 2.2, 3, 4 y 5 establece los requisitos para que pueda ser admitido en el tráfico jurídico, su única limitante estaría dada por la violación de la seguridad informática.

8. Ley 25. 506 de Firma digital y documentos electrónicos. Argentina, Ley 19.799/2002, 25 de marzo. Ley sobre Documentos Electrónicos, Firma Electrónica y Servicios de Certificación de dicha firma. - Santiago de Chile, Chile, 2002 y Ley 527/1999. Ley de Mensajes de Datos. - Bogotá, Colombia, 1999. están todas las formas capaces de contener información susceptible de influencia en el proceso y encierra en una misma categoría de reproducciones a las fotografías, películas cinematográficas, fotocopias, grabaciones mediante discos, cintas magnetofónicas, mapas, telegramas, cablegramas, radiogramas y cualquier otro medio adecuado que pueda servir para portar una información.

Por consiguiente, el articulado engloba dentro del catálogo de medios de prueba, los medios de reproducción de la palabra, el sonido y la imagen, y los instrumentos que permitan archivar y conocer o reproducir palabras, datos, cifras y operaciones matemáticas llevadas a cabo con fines contables o de otra clase.

Por otra parte el Decreto-Ley 241 del 2006, encaminado a insertar el proceso económico, con el consiguiente cambio de denominación de la disposición: Ley de Procedimiento Civil, Administrativo, Laboral y Económico, y que se utiliza supletoriamente en algunas cuestiones al proceso civil, establece en el artículo 777, para el proceso económico, a los documentos electrónicos y digitales como medios de pruebas en juicio, dejando claro la posibilidad que tienen las partes de presentarlo en cualquier proceso o realizarse de oficio por parte de juez competente; lo que refleja una idea más avanzada sobre el particular de la normativa vigente.

Los documentos electrónicos así emitidos deberán ser considerados como válidos y aceptados como medio de prueba de la celebración de contratos y otros actos jurídicos al estar garantizada su legitimidad, autenticidad y exactitud, por el cumplimiento de las normas técnicas de cifrado de información que rige en el país (FormentinZayas, 2013).

En este mismo orden, dada la inexistencia de una norma específica en cuanto al documento electrónico se han evacuado múltiples consultas formuladas por el Fiscal General de la República y el Presidente de la Junta de la Organización Nacional de Bufetes 
Colectivos al Tribunal Supremo Popular, en cuanto a la incorporación y utilización en los procesos judiciales de las nuevas tecnologías de la información y las telecomunicaciones, como medios y herramientas para hacer más efectiva y menos costosa la actividad jurisdiccional, lo que ha derivado la impartición de dictámenes e instrucciones por parte del Consejo de Gobierno de este órgano, función que le viene impuesta por mandato constitucional ${ }^{9}$.

A guisa de ejemplo, es factible referirse al Dictamen 446 de 2015, que reconoce la necesidad impostergable de incorporar la videoconferencia como medio eficaz para escuchar testimonios o declaraciones de personas que se encuentren en sitios muy distantes o impedidos de comparecer personalmente ante las autoridades judiciales, lo que supone su eficacia como medio de prueba cuando se realiza dentro del territorio nacional o se solicita para ser efectuada con otros países. En tal sentido, y dado que la introducción de la videoconferencia para la práctica de pruebas en los procesos judiciales, constituyó una novedad en el quehacer de los órganos jurisdiccionales, resultó necesario realizar determinadas precisiones sobre las pautas que deben seguir los tribunales para su instrumentación, lo que dio lugar a la impartición de la Instrucción 232 de 2016.

En la mencionada instrucción, entre otras cuestiones importantes, se establece que: el sistema de audio y video utilizados debe permitir la comunicación oral, directa y fidedigna, en tiempo real, entre el tribunal de conocimiento y la sede judicial en que se practica la prueba; para garantizar la seguridad jurídica y la utilidad procesal pertinentes, deberá registrarse

9. La Constitución de la República de Cuba en su artículo 148 establece que: Los tribunales constituyen un sistema de órganos estatales, estructurados con independencia funcional de cualquier otro. El Tribunal Supremo Popular ejerce la máxima autoridad judicial y sus decisiones son definitivas. A través de su Consejo de Gobierno ejerce la iniciativa legislativa y la potestad reglamentaria, toma decisiones y dicta normas de obligado cumplimiento por todos los tribunales y, sobre la base de la experiencia de estos, imparte instrucciones de carácter obligatorio para establecer una práctica judicial uniforme en la interpretación y aplicación de la ley. la información obtenida mediante acta y, siempre que sea posible, de forma digital, en soportes magnéticos asequibles, a fin de que resulten unidos a las actuaciones judiciales; para la eficacia de la diligencia probatoria de que se trate, se adoptarán las medidas de seguridad informática pertinentes, que impidan cualquier vulneración de su resultado; con independencia de la naturaleza del medio probatorio objeto de la diligencia, se cumplirán, de forma simultánea los términos y garantías procesales establecidos en las leyes de procedimiento $\mathrm{y}$ en las disposiciones aprobadas por el Consejo de Gobierno del Tribunal Supremo Popular; se habilitará un registro electrónico que asiente y salvaguarde la práctica de pruebas y sus resultas, de cara al efectivo control judicial de su real diligenciamiento.

Siguiendo esta misma línea, cabe referirse al Dictamen 450 de 2018, donde se establece la posibilidad de que los abogados y fiscales utilicen medios de cómputo, tales como laptop, tablet, data show u otros soportes contentivos de información, en las audiencias públicas que se celebren en todas las materias, siempre que así se solicite previamente al tribunal que esté conociendo del asunto y sea autorizado por este, con la previsión de que no podrán utilizarse estos medios para grabar o filmar los actos judiciales, debido a que todas las disposiciones para grabar y utilizar las videoconferencias en los procesos judiciales fueron contenidas en la Instrucción 232, a la que se hizo alusión con anterioridad.

Unido a lo anterior, y dada la compleja situación epidemiológica mundial y nacional que tuvo lugar por la pandemia de COVID 19 y que impidió durante más de seis meses los vuelos internacionales y, en consecuencia, la presencia de los inversionistas extranjeros en el territorio nacional para la formalización de los actos mercantiles relacionados con procesos de inversión extranjera, previamente aprobados por las autoridades cubanas y teniendo en cuenta la importancia de estos procesos para el desarrollo del país, se implementaron soluciones legales por parte del Ministerio de Justicia, en virtud de la Instrucción 8 de 2020, para garantizar la 
seguridad jurídica y la eficacia de estos actos en lo que sin desnaturalizar la esencia de la función notarial, se lograra la realización de los actos notariales vinculados con las modalidades de inversión extranjera, con carácter experimental por el término de un año, contado a partir de su entrada en vigor, en aras de evaluar sistemáticamente su desarrollo, mejorar este procedimiento y la calidad de los servicios notariales.

En consecuencia, se indicó que, en las situaciones excepcionales antes descritas, los mencionados actos se pueden celebrar con presencia virtual de alguna de las partes, conectadas con calidad y de forma segura con el notario, por medio de una plataforma de videoconferencia o cualquier otro medio técnico que tenga imagen y sonido, considerándose como actos y audiencias notariales auténticas. Empero, el sistema utilizado debe permitir y garantizar al notario la identificación de los otorgantes, la calificación de su capacidad y legitimación, la lectura en alta voz del documento y su escucha por los otorgantes, recibir la prestación del consentimiento, el secreto profesional y la protección de los datos de los comparecientes.

En relación con el acto de firma del documento notarial cuando concurran dichas situaciones excepcionales, la parte extranjera ratifica el acto en presencia del funcionario consular cubano en el país de que se trate, ratificación que se hace constar en escritura pública autorizada por este, que firma el compareciente, y la escritura complementa y se une al documento constitutivo.

En el supuesto de que en el país de que se trate no existe representación consular cubana, puede considerarse que el documento está firmado únicamente por el otorgante presencial y el notario, si la declaración del consentimiento de la parte con presencia virtual se prueba con la grabación de la sesión de la videoconferencia $\mathrm{u}$ otro medio admitido en derecho. No obstante, a pesar de la existencia de las disposiciones analizadas y el esfuerzo de las autoridades encargadas de su análisis y promulgación, tal posición todavía encuentra sus desaciertos en la práctica procesal cubana, porque ello depende -en gran medida- de los avances que se requieren en cuanto a las nuevas tecnologías de la información y las telecomunicaciones, razones que complejizan la admisión de este medio de prueba en el proceso y más en el proceso civil.

Lo cierto es que, los soportes informáticos deben ser introducidos como prueba documental, pues cumplen básicamente la misma función de representación que cumplían las formas escritas en soportes tradicionales, en consecuencia, se reclama al legislador la posibilidad de trasladar para este tipo de prueba el mismo criterio de valoración legal existente para la prueba de documentos privados, no impugnados por inauténticos, de tal suerte que si estos soportes informáticos son capaces de sustituir a un documento tradicional, el reconocimiento de este por la parte a quien perjudique debería constituir un supuesto de prueba tasada. De otro modo, se llega al absurdo de penalizar con la prueba libre la utilización de los avances informativos, premiando con la prueba legal el mantenimiento de formas tradicionales (Sanchis, 2002, p. 7).

\section{CONCLUSIONES}

El auge de las tecnologías de la información y la comunicación, así como el impacto de estas en las relaciones civiles y mercantiles; y, por ende, en el proceso, se ha convertido en un reto para el derecho procesal ancestral, con vistas a clasificar adecuadamente esta fuente de prueba novel, contenida en un medio no tradicional, por el tipo de soporte que la traslada.

Empero, si se sigue la pauta de que la forma que se produce, consta o lee mediante los medios electrónicos constituye una manifestación de la forma escrita -siempre que no sufra modificación alguna que vaya en contra la autenticidad del documento por vía electrónica-, puede entonces resolverse el vacío normativo de la legislación civil vigente, con una modificación de los preceptos en cuanto a la forma del acto 
escrito y la admisibilidad del documento electrónico como medio de prueba; en correspondencia con su símil en materia económica y mercantil, y se encontrará una respuesta a la desprotección jurídica que existe con respecto a esta materia.

En este sentido, interesan lo relacionado con la identidad de los contratantes y la confidencialidad de sus datos personales, la existencia y validez de sus declaraciones de voluntad, la autoría e integridad de sus mensajes electrónicos y el no rechazo del mensaje en su origen y destino, todo encerrado en su seguridad y validez jurídica.

Gracias a los grandes cambios que produjo la tecnología moderna en la forma de expresión de la voluntad en los actos jurídicos y que hace imposible negar que los documentos electrónicos puedan llegar a cumplir de hecho con los requisitos de las pruebas que analizan los jueces, e incluso las superen en integridad e inalterabilidad, características que el juez debe considerar en la valoración que de las pruebas realice; correspondiendo al funcionario judicial interpretar las leyes de manera tal que les confiera valor probatorio.

Por tanto, de acuerdo al principio de libertad de medios que postula que los elementos de prueba puedan ser introducidos al proceso con amplitud, se debe reconocer al documento electrónico con las mismas características que los documentos tradicionales, lo que permitiría al juzgador admitir u ordenar los medios de prueba que considere idóneos para formar su convicción, y más en tiempos de pandemia.

\section{REFERENCIAS BIBLIOGRÁFICAS}

» Delgado Knight, M.I. (2012) Algunas Reflexiones en torno a la legalidad, Cultura Jurídica y comportamiento ciudadano, Revista Contribuciones a las Ciencias Sociales, Mayo. Disponible en: www.eumed.net/rev/cccss/20/

» Carnelutti, F. (1940). La prueba civil. Ed. Arayú, Buenos Aires.

» Carnelutti, F. (1982). La prueba civil (trad. N. Alcalá-Zamora), Ediciones De Palma.

»Chillón-Medina, J.M. (2004). Derecho de las Telecomunicaciones y de las Tecnologías de la Información, Escuela Nacional de la Judicatura. Santo Domingo. ISBN: 9934-978-2-7.

» Diez-Picazo, L. (1993). Fundamentos del Derecho Civil patrimonial, vol. I - Introducción.Teoría del contrato, $6^{\underline{a}}$ edición, Madrid: Thomson-Civitas. ISBN: 9788447026654.

» Devis-Echandía, H. (2000). Compendio de la prueba judicial. Anotado y concordado por Alvarado Velloso, Adolfo, Tomo I, Versión 2000. Bogotá: Editores Rubinzal-Culzoni.

» Formentin-Zayas, Y.M (2011). Las nuevas tendencias de la contratación en Cuba: contratación electrónica, en Revista de Legislación y Jurisprudencia, No. 3, III Época, Año 2011, Madrid, ISSN: 0210-8518, pp. 337-366.

» Formentin-Zayas, Y.M. (2013). La firma electrónica, su recepción legal. Especial referencia a la ausencia legislativa en Cuba, en Revista del Instituto de Ciencias Jurídicas de Puebla, Derecho y Nuevas Tecnologías, Nueva Época, No. 31, Año VII, México, ISSN: 1870-2147 pp. 104-120.

» Goldschmitd, J. (2010). Derecho Procesal Civil (trad. L. PRIETO CASTRO), Editorial marcial Pons, Barcelona, ISBN: 978-84-9768-752-2. 
» Gómez-Colomer, J.L, et. al. (2001). Derecho Jurisdiccional. Tomo II: Proceso civil. Vol. 1. Valencia: Editorial Bosch. ISBN: 978-84-7698-076-7

» Gómez-Orbaneja, E. (2009). Derecho y Proceso (Estudios y Comentarios de Legislación.Edicion I, Volumen I, España: Editorial Thomson-Civitas. ISBN: 978-8447031-887.

» Kisch, W. (1940). Elementos de Derecho Procesal Civil (trad. L. PRIETO CASTRO), Edición 2, Vol. 4, Revistade Derecho Privado, Madrid.

» Mantecón, A. (2016). Teoría general de la prueba en el proceso civil. En I. Pérez (Ed.), Derecho Procesal Civil, La Habana: Editorial Universitaria Félix Varela.

» Mendoza-Díaz. J. (2005) “La prueba en el proceso civil”, en Revista Jurídica Justicia y Derecho, Tribunal Supremo Popular, No. 5, Año 3, diciembre, La Habana.

» Meneses, C. (2008). Fuentes de prueba y medios de prueba en el proceso civil. Revista IUS et Praxis, 14(2) 43-86.

» Montero, J. (2007). La prueba en el proceso civil. 5a edición. Madrid: Editorial Thomson.

» Pinochet Olave, R. (2002). "El Documento Electrónico y la prueba literal", en Revista Ius et Praxis, No. 2, año 8, Universidad de Talca, Chile.

$»$ Ramos, F. (1985). Derecho Procesal Civil. Tomo I. 2da. Edición, Barcelona: Editorial Librería Bosch.

» Sanchís, C. (2002). La prueba por medios audiovisuales y por instrumentos de archivo en la LEC 1/2000. Valencia: Editorial Tirant lo Blanch.

» Knight-Soto, I.(2011) El valor axiológico de los derechos fundamentales como elemento esencial en los procedimientos de extradición, en Contribuciones a las Ciencias Sociales,junio www.eumed.net/rev/cccss/12/

» Von-Ihering, R. (1947). De interés en los contratos, traducción española de Adolfo Posada, Ed. Atalaya, Buenos Aires.

\section{Legislación}

» Constitución de la República de Cuba (2019). En Gaceta Oficial No.5, Cuba: Asamblea Nacional del Poder Popular.

» Código Civil cubano (1987), Ley No. 59/1987 de 16 de julio. (Anotado y concordado), a cargo de Pérez Gallardo, Leonardo B., Ediciones ONBC, 2006.

» Dictamen 446 (2015), del Tribunal Supremo Popular, Publicado en la Gaceta Oficial Ordinaria de 19 de octubre de 2015.

» Dictamen 450 (2018), del Tribunal Supremo Popular. Publicado en la Gaceta Oficial Ordinaria de dede 2018.

» Instrucción 232 (2016), del Tribunal Supremo Popular, Publicado en Gaceta Oficial No. 1 ordinaria de 7 de enero de 2016.

» Instrucción 8 (2010), del Ministerio de Justicia. Publicada en la Gaceta Oficial N0. 45 Extraordinaria de 2 de septiembre de 2010.

» Ley 50 (2005), De las Notarías Estatales y su Reglamento, a cargo de Pérez Gallardo, (Compiladores), Compilación de Derecho Notarial, Separata de Anuario Iberoamericano de Derecho Notarial, número 4, 2005. 
» Ley de Procedimiento Civil, Administrativo, Laboral y Económico (2006), Ley No. 7/1977 de 19 de agosto, en Gaceta Oficial de la República de Cuba, Ordinaria, № 34, de 20 de agosto de 1977, modificada por el Decreto-Ley No. 241/2006, de 26 de septiembre, en Gaceta Oficial de la República de Cuba, № 33, Extraordinaria, de 27 de septiembre del 2006. Citado como LPCALE.

» Ley 527 (1999). Ley de Mensajes de Datos. - Bogotá, Colombia, 1999. Diario Oficial No. 43.673 de agosto de 1999.

» Ley 25.506 (2001), Ley de Firma Digital. - Buenos Aires, Argentina,11 de diciembre., 2001.

» Ley 19.799 (2002), Ley sobre Documentos Electrónicos, Firma Electrónica y Servicios de Certificación de dicha firma, Santiago de Chile, Chile, 2002. Promulgada el 26 de marzo del 2002. Publicada en el Diario Oficial el 12 de abril de 2002.

» Sentencia no RC.000580 de Tribunal Supremo de Justicia - Sala de Casación Civil de 6 de octubre de 2016, Venezuela. 